\title{
Identical Twins
}

National Human Genome Research Institute (NHGRI)

\section{Source}

National Human Genome Research Institute (NHGRI). Identical Twins.

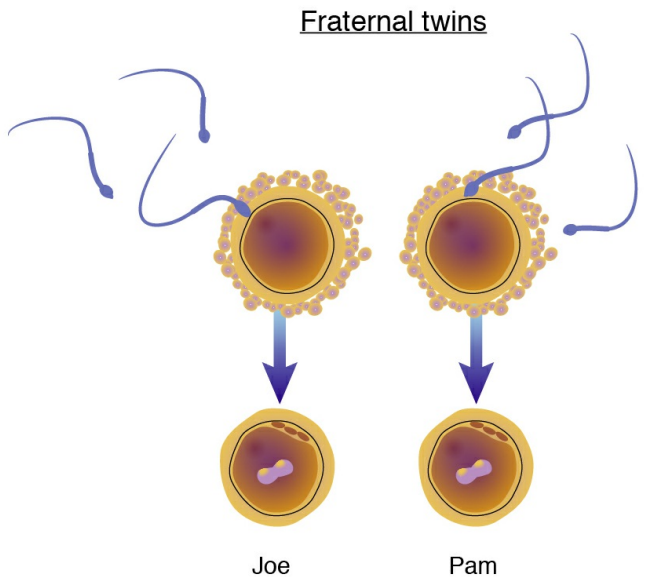

Identical twins

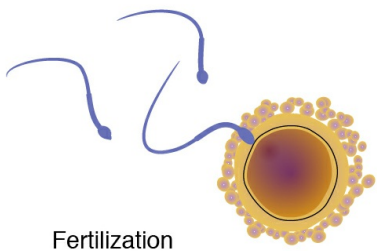

Fertilization

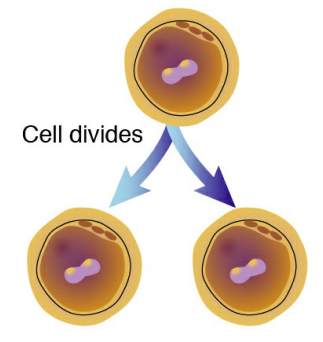

Sally

Sue

Identical twins are also known as monozygotic twins. They result from the fertilization of a single egg that splits in two. Identical twins share all of their genes and are always of the same sex. In contrast, fraternal, or dizygotic, twins result from the fertilization of two separate eggs during the same pregnancy. They share half of their genes, just like any other siblings. Fraternal twins can be of the same or different sexes. 